\title{
Consumo de forragem e desempenho de novilhas de corte recebendo suplementos em pastagem de azevém
}

\author{
Herbage intake and animal performance of beef heifers receiving supplements in Italian ryegrass \\ pasture
}

\section{Aline Tatiane Nunes da Rosa ${ }^{\mathrm{I}}$ Marta Gomes da Rocha ${ }^{\mathrm{I}}$ Luciana Pötter $^{\mathrm{I}}$ Gilberto Vilmar Kosloski $^{\mathrm{I}}$ Dalton Roso ${ }^{I}$ Renato Alves de Oliveira Neto ${ }^{I}$}

\section{RESUMO}

Foram estudados o desempenho, comportamento $e$ a ingestão de forragem por novilhas de corte em dois estádios de desenvolvimento do azevém (Lolium multiflorum Lam.): préflorescimento e florescimento. As novilhas permaneceram exclusivamente em pastejo ou em pastejo e recebendo grão de milho ou suplemento extrusado com gordura. $O$ delineamento experimental foi o inteiramente casualizado, em arranjo fatorial $3 \times 2$ (três sistemas alimentares $x$ dois estádios fenológicos do azevém). A ingestão de forragem foi estimada usando o óxido de cromo como indicador da produção fecal. Os valores médios de massa de forragem e oferta de lâminas foliares foram de $1636 \mathrm{~kg} \mathrm{ha}^{-1}$ de matéria seca (MS) e 2,3kg de MS $100 \mathrm{~kg}^{-1}$ de peso corporal $(P C)$, respectivamente. Novilhas que não receberam suplemento consumiram mais pasto sem diferir das que receberam gordura. Animais exclusivamente a pasto realizaram maior número de bocados diários. As ingestões de MS do pasto e total, que foram de 2,74 e 3,01\% do $P C$, respectivamente, são similares no pré-florescimento e florescimento do azevém. A ingestão de matéria seca total e os tempos de pastejo, ruminação e ócio de bezerras de corte recebendo suplementos são semelhantes ao uso exclusivo da pastagem de azevém, resultando em desempenho individual semelhante.

Palavras-chave: Lolium multiflorum, óxido de cromo, taxa de bocado.

\section{ABSTRACT \\ The performance, behavior and forage intake of grazing beef heifers at two phenological stages of Italian ryegrass (Lolium multiflorum Lam.): pre-flowering and flowering, were studied. The heifers remained exclusively on pasture or receiving corn grain or extruded supplement plus fat. The experimental design was completely randomized in a factorial $3 \times 2$ arrangement (three feeding systems $x$ two}

phenological stages of Italian ryegrass). The forage intake was evaluated using chromic oxide as a faecal production indicator. Mean values of herbage mass and leaf allowance were $1636 \mathrm{~kg}$ $\mathrm{ha}^{-1}$ of dry matter (DM) and $2.3 \mathrm{~kg}$ of DM $100 \mathrm{~kg}^{-1}$ live weight $(L W)$, respectively. Heifers kept exclusively on pasture consumed more grass without difference of those receiving fat. Heifers exclusively on pasture presented greater daily bite rate. The forage and total DM intake, which averaged 2.74 and $3.01 \%$ of $L W$, respectively, are similar at pre-flowering and flowering of ryegrass. The total forage DM intake and the grazing, rumination and idling times of beef heifers receiving supplements are similar to the use of the ryegrass exclusively, resulting in similar individual performance of heifers.

Key words: Lolium multiflorum, chromium oxide, bite rate.

\section{INTRODUÇÃO}

O consumo de forragem é o principal fator determinante do desempenho de animais em pastejo e é influenciado por vários fatores associados ao animal, ao pasto, ao ambiente e às suas interações. $\mathrm{O}$ fornecimento de suplementos para bezerras de corte em pastejo em azevém (Lolium multiflorum Lam.) permite que as bezerras apresentem maior altura, peso e escore de condição corporal e que estejam aptas para o primeiro acasalamento com menor idade (PÖTTER et al., 2010).

Dentre os suplementos para bovinos em pastejo, o grão de milho éo mais amplamente utilizado, sendo altamente palatável e também mais rico em gordura do que qualquer outro cereal, com teores entre

'Programa de Pós-graduação em Zootecnia, Universidade Federal de Santa Maria (UFSM), 97105-900, Santa Maria, RS, Brasil. E-mail: potter.luciana@gmail.com.*Autor para correspondência. 
3 e $6 \%$ de extrato etéreo; é pobre em fibra bruta e altamente digestível (NRC, 2001). Os efeitos do uso de suplementos ricos em lipídeos têm sido estudados na recria e na função reprodutiva de fêmeas de corte (FUNSTON et al., 2004). GUARDIEIRO et al. (2010) observaram que a suplementação com gordura protegida ruminal altera o metabolismo de progesterona, mas não altera a função ovariana em novilhas zebuínas. Embora exista vasta bibliografia disponível com relação ao uso de suplementos lipídicos, a maioria delas direciona-se aos sistemas de produção leiteira, com resultados focados em impactos na qualidade do leite e sem referência para a relação herbívoro/planta.

A importância da descrição do estádio fenológico da planta forrageira fundamenta-se na relação existente entre a idade da planta, sua estrutura e composição química, pois, em geral, as plantas perdem seu valor nutritivo com o avançar da idade pela diminuição na relação lâmina: colmo, pelo aumento da lignificação da parede celular (VAN SOEST, 1994). No azevém, com o avanço do seu ciclo fenológico, ocorre menor participação e redução na qualidade das folhas verdes. Em pastejo, para aumentar ou manter o consumo de forragem, os herbívoros podem empregar diferentes estratégias, seja por meio da variação do tamanho do bocado, do aumento da frequência de bocados ou pelo aumento do tempo de pastejo.

O objetivo deste trabalho foi avaliar o consumo de forragem e o desempenho de novilhas de corte submetidas a diferentes sistemas alimentares, nos estádios de pré-florescimento e florescimento do azevém, a partir da hipótese de que o fornecimento de diferentes suplementos energéticos e as alterações ocorridas na estrutura do pasto com o avanço do ciclo fenológico do azevém podem alterar o consumo de matéria seca e o desempenho dos animais em pastejo.

\section{MATERIAL E MÉTODOS}

O experimento foi desenvolvido na Universidade Federal de Santa Maria, de julho a novembro de 2009. O clima da região é Cfa (subtropical úmido), conforme classificação de Köppen. A temperatura média, no período experimental, foi de $17,5^{\circ} \mathrm{C}$. A insolação do período foi de 172,4 horas e a precipitação pluviométrica média, de 227,2mm.

Foram avaliados a ingestão de forragem, $o$ comportamento ingestivo de bezerras de corte e a estrutura da pastagem nos estádios de préflorescimento e florescimento do azevém (Lolium multiflorum Lam.), com bezerras exclusivamente em pastejo ou recebendo grão de milho $(0,78 \%$ de peso corporal (PC)) ou suplemento extrusado com gordura ( $0,2 \%$ do PC). O suplemento extrusado com gordura foi um produto comercial composto por milho moído, farelo de trigo, farelo de arroz integral, farelo de soja integral, calcário calcítico, fosfato bicálcico, óleo vegetal, sal e premix vitamínico mineral. A quantidade de cada suplemento, em percentagem do PC, foi ajustada para que os suplementos fossem isolipídicos, sendo que as bezerras receberam, em ambos os suplementos, $0,02 \%$ do PC de extrato etéreo. Os suplementos foram fornecidos diariamente às $14 \mathrm{~h}$ e, quando ocorriam sobras, estas eram recolhidas, secas e pesadas para posterior cálculo do consumo efetivo de suplemento. Os teores de proteína bruta e fibra em detergente neutro foram de 9,2 e 14,6\% e 12,8 e 29,6\% para grão de milho e gordura, respectivamente.

A pastagem de azevém foi estabelecida em maio de 2009, em área de cinco hectares, com seis subdivisões e 1,6 hectares em área anexa. O método de pastejo foi contínuo, com número variável de animais, para manter os valores de massa de forragem entre 1400-1600 kg ha-1 de matéria seca (MS) em todos os piquetes. Foram utilizadas 45 bezerras Abeerden Angus com idade de oito meses e peso inicial de $154 \pm 4,2 \mathrm{~kg}$. Foram utilizados três animais teste em cada unidade experimental e, dentre estes, dois foram dosificados, via oral, com óxido de cromo para determinação da excreção fecal e três foram utilizados para avaliação do comportamento ingestivo.

A massa de forragem ( $\mathrm{kg} \mathrm{ha}^{-1}$ de MS) foi avaliada por meio da técnica de estimativa visual com dupla amostragem a cada 28 dias. Na mesma ocasião, foram tomadas medidas da altura do dossel, com régua graduada, nos 20 pontos das avaliações visuais. Nas amostras provenientes dos cortes, foi realizada a separação botânica e estrutural dos componentes do azevém em lâminas foliares, colmos+bainha foliar, inflorescência, outras espécies e material morto. A taxa de acúmulo diário de forragem ( $\mathrm{kg}$ de $\left.\mathrm{MS} \mathrm{ha}^{-1} \mathrm{dia}^{-1}\right)$ foi determinada em três gaiolas de exclusão ao pastejo, por unidade experimental.

O ganho médio diário foi obtido pela diferença dos pesos inicial e final das novilhas em cada período experimental, dividido pelo número de dias deste. Por ocasião das pesagens, foi avaliado o escore de condição corporal com valores de 1 (muito magro) a 5 (muito gordo). A taxa de lotação, por período, foi obtida pelo peso médio dos animais teste mais o peso médio dos animais reguladores, multiplicado pelo número de dias que estes permaneceram na pastagem, dividido pelo número de dias do período de pastejo, sendo expressa em $\mathrm{kg} \mathrm{ha}^{-1}$ de PC.

Ciência Rural, v.43, n.1, jan, 2013. 
A disponibilidade de forragem $\left(\mathrm{kg} \mathrm{ha}^{-1} \mathrm{dia}^{-1}\right.$ de MS) foi obtida pela soma da taxa de acúmulo diário de forragem e da massa de forragem do período, dividida pelo número de dias deste. A oferta de forragem $(\mathrm{kg}$ de MS $100 \mathrm{~kg}^{-1}$ de PC) foi calculada pela divisão da disponibilidade de forragem pela carga animal. A oferta de lâminas foliares verdes foi obtida por meio da multiplicação da oferta de forragem pelo percentual de lâminas foliares na massa de forragem.

Para estimativa da ingestão de forragem, foi utilizado óxido de cromo $\left(\mathrm{Cr}_{2} \mathrm{O}_{3}\right)$ em pó, na forma de cápsulas, como indicador externo da produção fecal e a digestibilidade in vitro para determinação da digestibilidade da forragem. O método de dosificação foi manual, depositando a cápsula diretamente no fundo da cavidade oral. Cada novilha foi dosificada com 10,0g de $\mathrm{Cr}_{2} \mathrm{O}_{3}$, em uma dose diária às $12 \mathrm{~h}$. Operíodo de dosificação foi de 11 dias e, a partir do oitavo dia, foi realizada a coleta de fezes, direto no reto dos animais, duas vezes ao dia, durante os últimos quatro dias, em diferentes horários, com as amostragens realizadas a intervalos de três horas ao longo de um período de 24 horas. A concentração de cromo nas fezes secas foi determinada por espectrofotometria de absorção atômica. Para estimação da produção fecal $(\mathrm{PF})$, foi utilizada a fórmula: $\mathrm{PF}=$ cromo administrado ( $\left.\mathrm{g} \mathrm{dia}^{-1}\right) /$ cromo nas fezes $\left(\mathrm{g} \mathrm{kg}^{-1}\right.$ de MS) (POND et al., 1989). Avaliou-se a ingestão de MS (IMS, em $\mathrm{kg} \mathrm{dia}^{-1}$ ) pela fórmula: IMS=produção fecal/1digestibilidade e a ingestão de MS foi expressa em porcentagem do peso corporal.

Foram calculados os coeficientes de substituição (redução no consumo de MS do pasto por $\mathrm{kg}$ consumido de MS do concentrado) e adição (aumento no consumo total de MS). A determinação dos teores de proteína bruta, fibra em detergente neutro (AOAC, 1995) e a digestibilidade in vitro da matéria seca e orgânica da forragem foi realizada em amostras provenientes da simulação manual de pastejo, que foram previamente levadas à estufa de ar forçado à $55^{\circ} \mathrm{C}$, por 72 horas, depois moídas em moinho tipo Willey.

O teor de nutrientes digestíveis totais (NDT) da dieta foi estimado com base na composição química, utilizando-se o modelo matemático proposto por WEISS et al. (1992). Para o cálculo da energia digestível (ED, Mcal dia ${ }^{-1}$ ) e metabolizável da dieta (EM, Mcal dia ${ }^{-1}$ ), foi utilizada a metodologia descrita pelo NRC (1996).

Para avaliação do comportamento ingestivo, foram observados três animais teste por repetição de área por um período de $14 \mathrm{~h}$ ininterruptas, das $8 \mathrm{~h}$ às $18 \mathrm{~h}$, em 25/09 (estádio de pré-florescimento do azevém) e 23/ 10 (estádio florescimento). Foram avaliados, a intervalos de 10 minutos, o tempo total de pastejo, ócio e ruminação. Concomitantemente a essas observações, foram registrados, durante a manhã e a tarde, o número máximo possível de registros, com cronômetro, do tempo necessário para os animais realizarem 20 bocados.

O delineamento experimental foi o inteiramente casualizado, em arranjo fatorial $3 \times 2$ (três sistemas alimentares $\mathrm{x}$ dois estádios fenológicos do azevém). Foi realizada análise de variância utilizando-se o procedimento MIXED e, quando encontradas diferenças, as médias foram comparadas pelo recurso lsmeans. Quando não foram observadas diferenças entre tratamentos, eles foram agrupados para permitir o estudo de contrastes (milho x azevém e gordura). Devido ao elevado número de estruturas de covariância, foi realizado um teste de seleção da estrutura, utilizando o critério de informação de Akaike (AIC), para determinar o modelo que melhor representasse os dados. Para medir o nível de associação entre as variáveis avaliadas, foi realizado teste de correlação linear de Pearson em nível de 5\% de probabilidade. Os dados foram analisados utilizado o programa estatístico SAS (2001), versão 8.2.

\section{RESULTADOS E DISCUSSÃO}

Os dados foram coletados durante os estádios vegetativo, pré-florescimento e florescimento, mas houve excesso de chuvas por ocasião da coleta de dados no estádio vegetativo, ocasionando o encharcamento dos suplementos e impossibilitando o consumo da quantidade alvo prevista. Em setembro, a precipitação pluviométrica de $354,6 \mathrm{~mm}$ foi $125 \%$ superior à média histórica desse mês. Assim, só foram utilizados os dados coletados referentes aos estádios de pré-florescimento e florescimento do azevém.

Não houve interação $(P>0,05)$ estádios fenológicos do azevém $\mathrm{x}$ sistemas alimentares para massa de forragem, taxa de acúmulo de forragem, oferta de lâminas foliares, altura do dossel, proteína bruta (PB) e fibra em detergente neutro (FDN). Essas variáveis não diferiram entre os sistemas alimentares testados $(\mathrm{P}>0,05)$ e houve diferença entre os estádios fenológicos do azevém para taxa de acúmulo de forragem, oferta de lâminas foliares, altura do dossel e PB no pasto proveniente da simulação de pastejo (Tabela 1).

A massa de forragem (MF) média esteve dentro da faixa de valores entre 1100 a $1800 \mathrm{~kg} \mathrm{ha}^{-1} \mathrm{de}$ matéria seca (MS), na qual, em azevém, existe similar eficiência de transformação da forragem em produto animal (ROMAN et al., 2007). A taxa de acúmulo de forragem e a altura do dossel apresentaram os maiores valores no estádio de florescimento do azevém (Tabela 1) e correlacionaram-se de forma positiva entre si $(\mathrm{r}=0,75$; $\mathrm{P}=0,005)$. Os valores de taxa diária de acúmulo, em ambos os estádios (Tabela 1), foram $41,27 \%$ superiores 
Tabela 1 - Valores médios dos atributos da pastagem e do pasto, comportamento ingestivo e taxa de lotação de bezerras de corte submetidas a diferentes sistemas alimentares nos estádios pré-florescimento e florescimento do azevém.

\begin{tabular}{lcccc}
\hline Variáveis & Pré-florescimento & Florescimento & $\mathrm{P}^{8}$ & Média $\pm \mathrm{DP}$ \\
\hline Massa de forragem $^{1}$ & 1474 & 1797 & 0,063 & $1636 \pm 25,7$ \\
Taxa de acúmulo $^{2}$ & 53,0 & 79,0 & 0,004 & $66,4 \pm 2,4$ \\
Oferta lâminas $^{3}$ & 3,1 & 0,6 & 0,002 & $2,3 \pm 0,6$ \\
Altura do dossel $^{4}$ & 10,9 & 17,7 & 0,039 & $14,3 \pm 1,9$ \\
Proteína bruta $^{5}$ & 26,8 & 18,6 & 0,001 & $22,7 \pm 1,0$ \\
Fibra detergente neutro $^{5}$ & 55,6 & 58,6 & 0,164 & $57,2 \pm 1,7$ \\
Tempo pastejo $^{6}$ & 358,9 & 384,0 & 0,583 & $371,4 \pm 36,3$ \\
Tempo ruminação $^{6}$ & 159,4 & 210,0 & 0,290 & $184,7 \pm 42,4$ \\
Tempo ócio $^{6}$ & 312,2 & 228,7 & 0,034 & $270,4 \pm 65,7$ \\
Taxa de lotação $^{7}$ & 6,3 & 4,5 & 0,022 & $5,4 \pm 2,35$ \\
\hline
\end{tabular}

${ }^{1} \mathrm{~kg} \mathrm{ha}{ }^{-1} \mathrm{MS} ;{ }^{2} \mathrm{~kg} \mathrm{ha}^{-1} \mathrm{dia}^{-1} ;{ }^{3} \mathrm{~kg}$ MS $100 \mathrm{~kg}^{-1} \mathrm{PC} ;{ }^{4} \mathrm{~cm} ;{ }^{5} \% ;{ }^{6}$ minutos dia ${ }^{-1} ;{ }^{7}$ animal hectare ${ }^{-1} ;{ }^{8}$ probabilidade teste $\mathrm{F}$.

ao valor médio de $47,0 \mathrm{~kg} \mathrm{ha}^{-1}$ de MS observado em nove experimentos com azevém sob pastejo de novilhas de corte (PÖTTER et al., 2010).

Foram observados, no estádio de préflorescimento, os maiores valores de oferta de lâminas foliares e teor de PB (Tabela 1). Essas variáveis correlacionaram-se positivamente entre si $(r=0,94$; $\mathrm{P}<0,0001$ ), uma vez que a componente folha é a parte da planta com maior teor de nitrogênio. O conteúdo médio de FDN do pasto proveniente da simulação de pastejo esteve $2,2 \%$ acima do valor de $55 \%$, considerado limitante ao consumo de animais em pastejo (VAN SOEST, 1994). A ingestão total de MS (Tabela 2), no entanto, não foi afetada mesmo com esse valor de FDN, pois os valores observados de consumo resultaram em valores $0,2 \%$ superiores, em média, ao valor predito de $2,8 \%$ do peso corporal (PC) de bezerras de corte (NRC, 1996). Em pastagem de azevém, RIBEIRO FILHO et al. (2007), avaliando o efeito da quantidade de suplemento energético ( 2 e $4 \mathrm{~kg}$ de grão de milho moído vaca $^{-1}$ dia $^{-1}$ ) sobre o consumo de forragem de vacas leiteiras relataram teores de fibra em detergente neutro do pasto de $58,8 \%$, sem terem sido observadas limitações na ingestão de pasto e na produção de leite desses animais.

As ingestões de MS total e do pasto não sofreram interação estádios fenológicos do azevém $\mathrm{x}$ sistemas alimentares $(\mathrm{P}>0,05)$ e foram semelhantes nos dois estádios avaliados. Assim, a redução da oferta de lâminas em $416 \%$ do estádio de pré para o estádio de florescimento não limitou a ingestão de forragem pelas novilhas. A ingestão de MS do pasto foi maior para as bezerras exclusivamente em pastejo, intermediária para as novilhas que recebiam gordura, e inferior quando o suplemento utilizado foi o grão de milho (Tabela 2). $\mathrm{O}$ consumo de pasto pelas novilhas que recebiam gordura provavelmente visou a saciar a sua demanda energética, pois a ingestão de dietas com gordura pode fazer com que os animais em pastejo tenham essa demanda atendida mesmo ingerindo uma quantidade menor de pasto (GAGLIOSTRO \& CHILLIARD, 1992). A quantidade ingerida de gordura, $3 \%$ na MS da dieta, foi inferior ao limite de 5 a $6 \%$ na MS da dieta (PALMQUIST \& JENKIS, 1980). Conforme esses autores, valores maiores de gordura podem afetar a fermentação ruminal, pela formação de uma camada gordurosa em torno das partículas de fibra, dificultando a ação das bactérias celulolíticas no rúmen.

Novilhas exclusivamente em pastagem apresentaram consumo do pasto $13 \%$ superior às novilhas que receberam grão de milho como suplemento. Esse menor consumo pode ter sido ocasionado por uma substituição física de um alimento por outro, pois as novilhas recebiam, em média, 1,6kg $\operatorname{dia}^{-1}$ de MS de suplemento. A quantidade de grão de milho fornecida, $0,78 \%$ do $\mathrm{PC}$, foi consumida efetivamente na proporção de $0,60 \%$ do PC, possivelmente devido às perdas ocorridas no cocho por ocasião da alimentação. Com esse nível de ingestão, provavelmente a digestão da fibra não foi afetada negativamente, pois suplementos com elevada concentração de amido, como o grão de milho, não influenciam no desempenho animal ou a conversão do suplemento em ganho de peso, quando fornecidos até o nível de $0,7 \%$ do PC (HORN et al., 1995).

As novilhas ingeriram quantidade total de MS semelhante nos sistemas alimentares testados $(\mathrm{P}>0,05$; Tabela 2) e o grão de milho representou $21 \%$ do total de 
Tabela 2 - Ingestão de matéria seca do pasto e total, taxa de bocados e desempenho de bezerras de corte submetidas a diferentes sistemas alimentares em pastagem de azevém.

\begin{tabular}{lccccc}
\hline Variáveis & Azevém & Gordura & Milho & $\mathrm{P}^{1}$ & $\mathrm{CV}^{8}$ \\
\hline Ingestão MS do pasto $^{3}$ & $2,9 \mathrm{a}$ & $2,7 \mathrm{ab}$ & $2,6 \mathrm{~b}$ & 0,048 & 10,7 \\
Ingestão MS total $^{4}$ & 2,9 & 2,9 & 3,2 & 0,288 & 9,2 \\
Taxa de bocados $^{5}$ & $52,5 \mathrm{a}$ & $38,6 \mathrm{c}$ & $45,5 \mathrm{~b}$ & 0,002 & 3,1 \\
Ganho diário médio $^{6}$ & 1059 & 1005 & 1166 & 0,656 & 5,01 \\
Taxa de lotação $^{7}$ & 2,67 & 2,73 & 3,20 & 0,408 & 2,35 \\
\hline
\end{tabular}

${ }^{1}$ probabilidade teste F; ${ }^{2}$ probabilidade interação tratamento x estádios; ${ }^{3} \% \mathrm{PC} ;{ }^{4}$ suplemento + pasto; $^{5}$ bocados minuto $^{-1} ;{ }^{6} \mathrm{~g}^{\text {animal }}{ }^{-1}$ dia ${ }^{-1}$; ${ }^{7}$ animal hectare ${ }^{-1} ;{ }^{8}$ coeficiente de variação(\%).

Letras diferentes, na linha, diferem entre si pelo teste $l$ smeans a $5 \%$ de probabilidade.

MS ingerido diariamente, enquanto a gordura representou apenas $7 \%$. A disponibilidade alta de forragem pode ter sido responsável pela similaridade de ingestão da MS total, com redução da ingestão do pasto em consequência do consumo do suplemento energético.

As bezerras que receberam suplemento deixaram de ingerir 0,95 e $0,27 \mathrm{~kg}$ de MS do pasto para cada kg de MS ingerido de gordura e grão de milho, respectivamente, ou seja, uma taxa de substituição 3,5 vezes maior quando as novilhas consumiram gordura. Bezerras consumindo gordura deixaram de ingerir 466 gramas de pasto quando ingeriram 480 gramas desse suplemento, enquanto bezerras que receberam grão de milho deixaram de ingerir 432 gramas de pasto ao ingerir $1,6 \mathrm{~kg}$ de grão de milho moído. As taxas de adição verificadas não foram suficientes para provocar aumentos significativos na ingestão total de MS pelas novilhas.

Não houve interação $(\mathrm{P}>0,05)$ entre os estádios fenológicos do azevém $\mathrm{x}$ sistemas alimentares para ganho médio diário e taxa de lotação. O ganho médio diário das bezerras foi semelhante $(\mathrm{P}>0,05$; Tabela 2), independente do suplemento recebido e do estádio fenológico do azevém ( $\mathrm{P}>0,05)$, com valor médio de $1077 \mathrm{~g}_{\text {animal }}{ }^{-1}$ dia $^{-1}$. A ingestão total de MS não diferiu entre os diferentes sistemas alimentares e isso pode explicar o desempenho semelhante das bezerras mesmo com diferentes taxas de ingestão de MS do pasto. As bezerras mantidas exclusivamente em azevém ingeriram 1,7 e 4,1 $\mathrm{kg} \mathrm{dia}^{-1}$ de PB e FDN e esses valores foram, em média, 0,02 e 0,09\% menores, respectivamente, quando as bezerras receberam suplemento. $\mathrm{O}$ valor de ganho médio diário observado foi $26 \%$ superior ao valor de $852,6 \mathrm{~g}$, relatado por PÖTTER et al. (2010) para um conjunto de nove experimentos realizados com diversos níveis e tipos de suplementos para bezerras de corte em pastagens cultivadas de estação fria.
A taxa de lotação foi semelhante $(\mathrm{P}>0,05$; Tabela 2) entre os sistemas alimentares testados. Pelo estudo de contrastes (grão de milho x gordura extrusada e azevém), o fornecimento de grão de milho ocasionou taxa de lotação $18 \%$ superior aos demais sistemas testados $(\mathrm{P}=0,011)$ e essa superioridade foi devida ao efeito substitutivo observado quando as novilhas receberam milho. $\mathrm{O}$ valor $49 \%$ superior da taxa de acúmulo de forragem observado no estádio de florescimento do azevém (Tabela 1) foi responsável pelo incremento de $41 \%$ na taxa de lotação nesse estádio em relação ao de pré-florescimento (Tabela 1).

A taxa de bocados não sofreu interação $(\mathrm{P}>0,05)$ nos estádios fenológicos do azevém $\mathrm{x}$ sistemas alimentares testados, e também não diferiu entre os estádios fenológicos do azevém. A taxa de bocados foi superior para as bezerras que permaneceram exclusivamente em pastagem de azevém, intermediária para o recebimento de grão de milho e menor quando as bezerras receberam gordura como suplemento (Tabela 2). Os herbívoros tendem a variar a taxa de bocados conforme a manipulação necessária para a ingestão da forragem (HODGSON et al., 1994), uma vez que a estrutura da pastagem não foi alterada quando os animais receberam diferentes suplementos (Tabela 1) essa diferença observada não pode ser explicada por meio das variáveis coletadas.

Os tempos de pastejo, ruminação e ócio foram semelhantes $(\mathrm{P}>0,05)$ para as novilhas que recebiam os diferentes suplementos, com média de 369,3, 182,8 e 274,3 minutos $\mathrm{dia}^{-1}$, respectivamente, embora KRYSL \& HESS (1993) afirmem que o aumento nos níveis de amido nos suplementos reduz o tempo gasto pelo herbívoro com o pastejo. O nível de grão de milho utilizado, em relação ao peso corporal, provavelmente, não foi suficiente para provocar essa mudança. 
Os tempos de pastejo e ruminação não diferiram com o avanço do ciclo fenológico do azevém (P>0,05; Tabela 1). O tempo de ócio foi reduzido em $36,5 \%$ do estádio de pré-florescimento para o florescimento, e correlacionou-se de forma positiva $(\mathrm{r}=0,65 ; \mathrm{P}=0,021)$ com a oferta de lâminas foliares, que foi maior no pré-florescimento. As atividades comportamentais são mutuamente excludentes e a redução no tempo de ócio do estádio de préflorescimento para o florescimento foi acompanhada por uma alteração, na mesma proporção, no tempo de ruminação de $32 \%$. As folhas são selecionadas primeiro pelos animais em pastejo e, com a redução de disponibilidade desse componente, os animais consomem outras partes das plantas (KRYSL \& HESS, 1993) e esse fato pode alterar o tempo de ruminação.

\section{CONCLUSÃO}

Em pastos de azevém, a suplementação com grão de milho ou gordura, na proporção de 0,78 e $0,2 \%$ do peso corporal, respectivamente, não afeta a ingestão total de MS e o desempenho individual de bezerras de corte, independente do estádio de desenvolvimento da forragem.

\section{COMITÊ DE ÉTICA E BIOSSEGURANÇA}

Os autores responsáveis por este artigo assumem a responsabilidade pelas condições experimentais a que os animais foram submetidos, declarando que o trabalho foi realizado conforme os Princípios Éticos na Experimentação Animal e respeitando o seu bem-estar.

\section{REFERÊNCIAS}

ASSOCIATION OF OFFICIAL ANALYTICAL CHEMISTRY (AOAC). Official methods of analysis. 16.ed. Arlington: AOAC International, 1995. 1025p.

FUNSTON, R.N. Fat supplementation and reproduction in beef females. Journal of Animal Science, v.82, p.154-161, 2004. Disponível em: <http://jas.fass.org/content/82/13 suppl>. Acesso em: 16 jun. 2012.

GAGLIOSTRO, G.A.; CHILLIARD, Y. Revisión bibliográfica. Utilización de lípidos protegidos en nutrición de vacas lecheras. I. Efecto sobre la producción y la composición de la leche y sobre la ingestión de materia seca y energía. Revista Argentina de Producción Animal, v.12, n.1, p.1-15, 1992.

GUARDIEIRO, M.M. Função ovariana de novilhas Nelore alimentadas com dieta Suplementada com gordura protegida ruminal. Pesquisa Agropecuária Brasileira, v.45, n.4, p.408414, 2010. Disponível em: <http://webnotes.sct.embrapa.br/ pab>. Acesso em: 16 jun. 2012.

HODGSON, J. et al. Foraging behavior in grazing animals and its impact on plant communities. In: FAHEY, G.C. National conference on forage quality, evaluation and utilization. Nebraska: University of Nebrasca, 1994. p.796-827.
HORN, G.W. et al. Influence of high-starch vs high-fiber energy supplements on performance of stocker cattle grazing wheat pasture and subsequent feedlot performance. Journal of Animal Science, v.73, n.1, p.45-54, 1995. Disponível em: <http://jas.fass.org/content/73/1/45>. Acesso em: 24 ago. 2011.

KRYSL, L.J.; HESS, B.W. Influence of supplementation on behavior of grazing cattle. Journal of Animal Science, v.71, n.9, p.2546-2555, 1993. Disponível em: <http:// jas.fass.org/content/71/9/2546>. Acesso em: 25 ago. 2011.

NATIONAL RESEARCH COUNCIL (NRC). Nutrient requirements of beef cattle. 7.ed. Washington, D.C.: National Academy, 1996. 248p.

NATIONAL RESEARCH COUNCIL (NRC). Nutrient requirements of dairy cattle. 7.ed. Washington D.C.: National Academy, 2001. 408p.

PALMQUIST, D.L.; JENKIS, T.C. Fat in lactation rations: review. Journal of Dairy Science, v.63, n.1, p.1-14, 1980. Disponível em: <http://download.journals.elsevierhealth.com/ pdfs/journals/0022-0302/PIIS0022030280828815.pdf>. Acesso em: 25 ago. 2011. doi: 10.3168/jds.S00220302(80)82881-5.

POND, K.R. et al. Passage of chromium-mordanted and rare earth-labeled fiber: time of dosing kinetics. Journal Animal Science, v.67, n.4, p.1020-1028, 1989. Disponível em: <http:/ /jas.fass.org/content/67/4/1020>. Acesso em: 25 ago. 2011.

PÖTTER, L. et al. Suplementação com concentrado para novilhas de corte mantidas em pastagens cultivadas de estação fria. Revista Brasileira de Zootecnia, v.39, n.5, p.992-1001, 2010. Disponível em: <http://www.scielo.br/scielo.php?script=sci_arttext\&pid=S151635982010000500008\&lng=en\&nrm=iso>. Acesso em: 09 ago. 2010. doi: 10.1590/S1516-35982010000500008.

RIBEIRO FILHO, H.M.N. et al. Suplementação energética para vacas leiteiras pastejando azevém com alta oferta de forragem. Revista Brasileira de Zootecnia, v.36, n.6, supl., p.2152-2158, 2007. Disponível em: <http://www.scielo.br/pdf/ rbz/v36n6s0/27.pdf>. Acesso em: 25 ago. 2011. doi: 10.1590/ S1516-35982007000900025.

ROMAN, J. et al. Comportamento ingestivo e desempenho de ovinos em pastagem de azevém anual (Lolium multiflorum Lam.) com diferentes massas de forragem. Revista Brasileira de Zootecnia, v.36, n.4, p.780-788, 2007. Disponível em: <http://www.scielo.br/pdf/\%0D/rbz/v36n4/05.pdf〉. Acesso em: 25 ago. 2011. doi: 10.1590/S1516-35982007000400005.

SAS INSTITUTE. Statistical analysis user's guide. Version 8.2. Cary, 2001. 1686p.

VAN SOEST, P.J. Nutritional ecology of the ruminant. 2.ed. Ithaca: Cornell University, 1994. 476p.

WEISS, W.P. et al. A theoretically-based model for predicting total digestible nutrient values of forages and concentrates. Animal Feed Science and Technology, v.39, n.1-2, p.95-110, 1992. Disponível em: <http://www.sciencedirect.com.ez45.periodicos.capes.gov.br/ science?_ob=MImg\&_imagekey=B6T42-49N8SX4$1 \mathrm{C} 1 \& \mathrm{cdi}=4962 \&$ user $=923856 \& \mathrm{pii}=0377840192900344 \&$ origin =browse $\&$ coverDate $=11 \% 2 \mathrm{~F} 16 \% 2 \mathrm{~F} 1992 \&$ sk=999609998 \&view $=$ $\mathrm{c} \& \mathrm{wch} \mathrm{p}=\mathrm{dGLzVzz}-\mathrm{zSkzV} \& \mathrm{md} 5=6 \mathrm{~d} 6 \mathrm{f} 966 \mathrm{ec} 0$ e $\mathrm{a} 939 \mathrm{~d}$ 99cee8b5d2475820\&ie=/sdarticle.pdf . Acesso em: 25 ago. 2011. doi: 10.1016/0377-8401(92)90034-4. 